\title{
DIGNIDADE, DIREITOS FUNDAMENTAIS E DIREITOS DA PERSONALIDADE: UMA PERSPECTIVA GARANTISTA PARA A DEMOCRACIA SUBSTANCIAL
}

\author{
DIGNIDAD, DERECHOS FUNDAMENTALES Y DERECHOS DE \\ PERSONALIDAD: UNA PERSPECTIVA GARANTISTA PARA LA \\ DEMOCRACIA SUBSTANCIAL
}

\section{DIGNITY, FUNDAMENTAL RIGHTS AND PERSONALITY RIGHTS: A GUARANTEE PERSPECTIVE FOR SUBSTANTIAL DEMOCRACY}

\begin{abstract}
JOSÉ SEBASTIÃO DE OLIVEIRA
Pós-Doutor pela Fac. Direito da Universidade de Lisboa (Portugal).Doutor em Direito das Relações Sociais (PUC/SP). Professor do Programa de Doutorado e Mestrado em Ciências Jurídicas do Centro Universitário de Maringá (UNICESUMAR). Membro do Conselho Nacional de Pesquisa e Pos Graduação em Direito. e Advogado no Paraná.drsjo@brturbo.br

DIEGO PREZZI SANTOS

Doutor em Direito (FADISP). Mestre em Direito (UNICESUMAR).Membro do Conselho Nacional de Pesquisa e Pós Graduação em Direito. Professor e Advogado. E-mail: diegoprezzi@yahoo.com.br
\end{abstract}

\section{RESUMO}

Objetivo: O objetivo deste artigo é pensar o constitucionalismo a partir da atividade da ponderação e do garantismo judiciário, visando atingir o Estado legal para o 
democrático e social de direito, por meio da análise da teoria do garantismo jurídico de Luigi Ferrajoli.

Metodologia: O método utilizado é o dedutivo através de uma avaliação doutrinária de literatura jurídica nacional e estrangeira a respeito de conceitos de dignidade, constitucionalismo, ponderação e garantismo.

Resultados: O presente estudo apontou como resultado o pensamento de Luigi Ferrajoli, autor florentino, a respeito do direito e da razão na diminuição do poder do Estado e na perspectiva de uma maior proteção à pessoa, por meio de um máximo de construção de garantias e direitos fundamentais, na perspectiva da elevação do princípio da dignidade da pessoa humana.

Contribuições: A principal contribuição deste estudo é enaltecer o modelo de Estado defendido na teoria de Luigi Ferrajoli como detentor do poder, porém, atrelado ao dever de abstenção da proteção positiva em favor da pessoa. Ainda, o contributo deste artigo é sobressair a soberania popular por meio da legitimação dos representantes via eleição periódica com pluralismo de opções e submissão dos governantes à lei e à Constituição, a fim de preservá-la, mas também de conferir tutela de direitos e garantias individuais e sociais dos seus destinatários.

Palavras-chave: Dignidade da pessoa humana; direitos fundamentais; direitos da personalidade; garantismo; democracia.

\section{RESUMEN}

Objetivo: El objetivo de este artículo es pensar en el constitucionalismo basado en la actividad de la ponderación y garantía del poder judicial, con el objetivo de alcanzar el Estado legal para el derecho democrático y social, a través del análisis de la teoría de la garantía legal de Luigi Ferrajoli.

Metodología: El método utilizado es el deductivo a través de una evaluación doctrinal de la literatura legal nacional y extranjera con respecto a los conceptos de dignidad, constitucionalismo, ponderación y garantía.

Resultados: El presente estudio señaló, como resultado, el pensamiento de Luigi Ferrajoli, un autor florentino, sobre el derecho y la razón en la disminución del poder del Estado y en la perspectiva de una mayor protección de la persona, a través de un máximo de construcción de garantías y derechos fundamentales, con vistas a elevar el principio de dignidad humana.

Contribuciones: La principal contribución de este estudio es resaltar el modelo de Estado defendido en la teoría de Luigi Ferrajoli como titular del poder, sin embargo, vinculado al deber de abstenerse de una protección positiva a favor de la persona. 
Aún así, la contribución de este artículo es destacar la soberanía popular a través de la legitimación de los representantes a través de elecciones periódicas con pluralismo de opciones y sumisión de los gobernadores a la ley y la Constitución, para preservarla, pero también para conferir protección de derechos y garantías individuales y sociales de sus destinatarios.

Palabras clave: Dignidad de la persona humana; derechos fundamentales; derechos de personalidad; garantismo; democracia.

\section{ABSTRACT}

Objective: The objective of this paper is to think about constitutionalism based on the activity of balancing and guaranteeing of judiciary, aiming to reach the legal State for the democratic and social law, through the analysis of Luigi Ferrajoli's theory of legal guarantee.

Methodology: The method used is the deductive one through a doctrinal assessment of national and foreign legal literature regarding concepts of dignity, constitutionalism, balancingn and guarantee.

Results: The present study pointed out, as a result, the thought of Luigi Ferrajoli, a Florentine author, regarding the right and reason in the decrease of the State's power and in the perspective of greater protection to the person, through a maximum of construction of guarantees and fundamental rights, with a view to raising the principle of human dignity.

Contributions: The main contribution of this study is to highlight the State model defended in Luigi Ferrajoli's theory as the holder of power, however, linked to the duty to abstain from positive protection in favor of the person. Still, the contribution of this article is to highlight the popular sovereignty through the legitimation of the representatives through periodic election with pluralism of options and submission of the governors to the law and the Constitution, in order to preserve it, but also to confer protection of individual and social rights and guarantees of its recipients.

Keywords: Human dignity; fundamental rights; personality rights; guarantee; democracy. 


\section{INTRODUÇÃO}

O homem é um ser coexistencial (PRADO, 2014, p.57). A vida comunitária é parte de sua natureza, por isso, nela vive e se desenvolve alcançando feitos que, sozinho, não seria possível. O Direito surge como uma das formas de regular essa vida comunitária conforme os parâmetros sociais cunhados no contrato social.

A ideia de uma Constituição não é algo novo, não tendo surgido no século passado, apesar de ter sido este o período da consolidação do constitucionalismo.

De fato, esse movimento para constitucionalizar o Direito tem na Inglaterra e na Carta Magna um importante momento, posto que houve limitação ao poder real absoluto com o devido processo legal (ABBOUD; CARNIO; OLIVEIRA, 2015, p.275).

A Revolução Gloriosa que culminou com o parlamentarismo e o Bill of Rights (1688) (TAVARES, 2012, p.79), a Declaração de Direitos do Bom Povo da Virgínia (1776), a Constituição Federal dos Estados Unidos da América (1787) e a Declaração de Direitos do Homem e do Cidadão (1789) (CARBONELL, 2008, p.9) são também importantes documentos.

Precisa-se atentar que se outros momentos históricos e documentos estabeleceram o Estado Legislativo, foi justamente com as nações saídas do grande conflito que o Direito e a Política foram alteradas (GUERRA FILHO, 2013, p.172-173). As mudanças drásticas que se deram com o desfecho da 22ª . Guerra Mundial manejaram reforço nas Constituições que continham não só normas de criação e organização do Estado, mas também direitos individuais e direitos sociais (LUISI, 2003, p.11).

O primado da Constituição sobre a lei, a reserva de Constituição e o controle de constitucionalidade foram decisivos para a mudança do Estado Legislativo para o Democrático e Social de Direito (PRADO, 2019, p. 72-74).

No Brasil, tardiamente houve manifestação deste movimento, que já estava estabelecida na Europa e em outros Estados (OLIVEIRA, 2002, p.90-91).

$\mathrm{Na}$ Constituição Federal de 1988 dispõe-se, desde seu preâmbulo, em um Estado Democrático de Direito, assim como no seu primeiro artigo, que também estabelece os princípios de fundamentação do modelo, sendo que todo restante do 
texto constitucional é a "explicitação do conteúdo dessa formula política" (GUERRA FILHO, 2013, p.170).

\section{DIGNIDADE HUMANA}

No centro desta fórmula política há, dentre os princípios, no inciso III do art. $1^{\circ}$. da Constituição a dignidade da pessoa humana.

Insta esclarecer que, com o Cristianismo, a ideia de pessoa como um fim em si mesma passa a ter lugar; o ser humano é um fim absoluto em si, possuidor de direitos, tem, então, dignidade. Como reflexo de tal concepção, a pessoa não pode ser meio, não é coisa, não é mero cidadão e sim pessoa, independentemente de ligações políticas ou jurídicas (PRADO, 2019, p.102).

Transportou-se tal concepção para o sistema jurídico, com evolução e involuções em tempos e locais distintos.

No Brasil, na Lei Fundamental de 1988, tal princípio não é mera "criação legislativa, visto que apenas se reconhece no texto constitucional a eminência da dignidade como valor (ou princípio) básico, cuja existência bem como o próprio conceito de pessoa humana, são dados anteriores" (PRADO, 2019, p.103).

E essa norma pode ser visualizada de dois aspectos, tanto quanto "qualidade substancial do ser humano, a dignidade como sendo a expressão da essência da pessoa humana e, de outro, o fundamento da ordem política e de paz social, revelando-se uma fonte de direitos" (SZANIAWSKI, 2005, p.143).

Caracteriza-se como categoria lógico-objetiva, um atributo ontológico do homem (PRADO, 2019, p.102). Esta concepção reflete a dignidade como elemento intrínseco à pessoa, "qualidade intrínseca e distintiva reconhecida em cada ser humano que o faz merecedor do mesmo respeito e consideração por parte do Estado e da comunidade, implicando, neste sentido, um complexo de direitos e deveres fundamentais" (SARLET, 2012, p.73) e, também, como fundamento do Direito.

Situa-se, portanto, a dignidade no centro do Ordenamento e faz que as demais normas, as decisões e as políticas sejam adequadas ao conteúdo que dela emana, já 
que a "dignidade da pessoa é princípio fundamental da República Federativa do Brasil" (FACHIN, 2001, p.190).

Trata-se de um princípio estruturante que "ganha concretização por meio de outros princípios e regras constitucionais formando um sistema interno harmônico, e afasta, de pronto, a ideia de predomínio do individualismo atomista no Direito" (FACHIN, 2001, p.190).

A Dignidade é elemento indissociável da criação, da fundamentação e da definição de sentido dos princípios de direito (COMTE-SPONVILLE, 1999, p.90), dos direitos fundamentais e dos direitos da personalidade (BONILLA SÀNCHEZ, 2010, p.31).

E a norma violadora da dignidade da pessoa humana deve ser reputada de inconstitucional, e o desrespeito aos direitos fundamentais ou aos princípios também afetam a dignidade, pois se trata do próprio fundamento destas normas (PRADO, 2019, p.103).

\subsection{DIREITOS FUNDAMENTAIS E DIREITOS DA PERSONALIDADE}

Conquanto tenham se estabelecido no Estado liberal, os direitos fundamentais são itens extremamente relevantes do Estado democrático e social de Direito. O "ordenamento jurídico positivo confere específica estrutura e conteúdo a uma comunidade social, garantindo os direitos individuais (ABBOUD, 2011, p.342), as liberdades públicas, a legalidade e a igualdade formais, mediante uma organização policêntrica dos poderes públicos e a tutela judicial dos direitos" (PRADO, 2019, p.113).

Estes direitos têm tutela constitucional e civil, ambas com foco semelhante e com repercussão constitucional. Em seu núcleo, há a identidade de que a Dignidade é a origem dos direitos fundamentais e da personalidade. Salienta-se serem: 
E são "aqueles direitos inerentes à pessoa e à sua dignidade. Surgem cinco ícones principais: vida/integridade física, honra, imagem, nome e intimidade. Essas cinco expressões-chaves demonstram muito bem a concepção desses direitos" (TARTUCE, 2005).

Existe um mesmo fundamento (dignidade e Constituição), um mesmo objetivo (proteção humana) e tutelas distintas, mas que se somam para conter o Estado e terceiros contra intervenções indevidas na esfera individual.

Há "assim um encontro de grande jurídica entre o direito privado, a liberdade pública e o direitos constitucional" (FERMENTÃO, 2006, p.241-266). E a conclusão é que ao Estado cabe propiciar meios do ser humano viver em paz, desenvolver seu potencial, sendo vedadas máculas à sua individualidade, uso da pessoa como meio para o a consecução de fins pessoais ou estatais, entre outros referencias de vultosa relevância.

\section{CONTRIBUIÇÕES DO GARANTISMO AOS DIREITOS FUNDAMENTAIS E DE PERSONALIDADE}

Há que ser feito um alerta de vulto, qual seja, "a simples elaboração de um texto constitucional, por melhor que ele seja, não é suficiente para que o ideário que o inspirou introduza-se efetivamente nas estruturas sociais" (GUERRA FILHO, 2013, p.170).

E a crise de legalidade, de legitimidade, a violação sistemática de direitos fundamentais, o mega encarceramento, são alguns dos indicativos de um cenário que mostra o Direito sendo sabotado e sabotando o convívio social.

Apesar de diversas causas para o caos no mundo jurídico, há na doutrina crítica bastante importante a relativização de princípios, direitos fundamentais e a normatividade fraca destas normas.

Cumpre ilustrar que as normas são classificadas, majoritariamente, por seu grau de abstração. Regras são precisas e aplicadas via subsunção, enquanto 
princípios são abstratos, vagos e indeterminados e têm aplicação por ponderação (CANOTILHO, 1998, p. 1123-1125). As regras são dotadas de significado preciso e os princípios de significado elástico (GUASTINI, 2005, p.188).

Sabe-se que a mecânica regular de aplicação de princípios e direitos fundamentais é a proporcionalidade como meio de ponderação que conta com desenvolvimento teórico importante (GUERRA FILHO, 2002, p. 84). Contudo, tal mecânica não escapa à crítica de que a "Proporcionalidade tem ocupado posição de destaque na construção dos ordenamentos jurídicos contemporâneos, apesar de sua ainda insuficiente elaboração teórica" (TAVARES, 2002, p. 518).

Em especial, a forma como se dá a proporcionalidade não cumprindo com as etapas e a racionalidade ${ }^{1}$ com que fora estruturada (ALEXY, 2009, p. 56-65), sendo confundida com razoabilidade (CARNIO, 2011, p.101-112), é alvo de críticas bastante severas, posto que permitem a já mencionada relativização e a fraca normatividade.

Há geração de normatividade fraca dos princípios e direitos fundamentais (FERRAJOLI2011, p. 11-53).

E um excesso de oscilação de decisões judiciais em razão do uso da técnica ou de um uso desregrado desta, sem perpassar pelas etapas e pela maneira de realizá-las estabelecida doutrinariamente (BARROS, 2003, p. 76/77). E isso se faz com o lançamento de noções morais do responsável pela ponderação, ou seja, seu próprio sentimento de justiça.

Uma das mais relevantes críticas advém de Winfried Hassemer (2008, p.99104), para quem "conjunturas são de tal forma construídas que já a própria escolha dos caminhos implica a solução: quem permite uma ponderação entre os danos ameaçadores e os princípios ameaçados, já neste ponto da reflexão abriu mão dos princípios".

Há, com o exercício ponderativo, um princípio lançado no "cálculo" somente para funcionar como sparring. Outra crítica é a de que, sendo os direitos fundamentais e princípios limites, a indisponibilidade é a regra e a possibilidade de deles disporem por ponderação é excepcionalíssima (MAIHOFER, 2008, p.29-33).

${ }^{1}$ A esse respeito, indispensável a leitura de STRIQUER SOARES; LIMA, 2012, p. 3-16. 
Luigi Ferrajoli apresenta contraponto ao que é considerada a vantagem do neoconstitucionalismo. Essa contraindicação é justamente a concepção de direitos fundamentais como princípios morais a serem aplicados por ponderação, com pesos diferentes (DWORKIN, 2002, p.42/43) não é uma vantagem (HABERMAS, 1997, p.252/253).

E, contrariamente a esse enfraquecimento da carga normativa, há a própria noção de Estado democrático e social de Direito (ou Estado Constitucional para usar a expressão do Mestre de Camerino).

\subsection{O POSITIVISMO REFORÇADO E A LEGALIDADE}

Um dos pilares do garantismo é a legalidade.

A leitura feita pelo professor florentino é de que a mera legalidade consiste na base do Estado legislativo de Direito por criar, organizar e limitar a atuação estatal em normas jurídicas positivas. E estas são reputadas válidas pelo fato de terem sido corretamente produzidas, i.e., por terem seguido processo legislativo (FERRAJOLI, 2014, p. 19).

O autor chama de estrita legalidade a necessidade das normas serem condicionadas por outras normas, gerando limites e conteúdos com base nos direitos fundamentais, garantias. Um dos exemplos dessa estrita legalidade são os capítulos de direitos da personalidade no Código Civil, criados pelo condicionamento das normas civis pelas constitucionais.

É de salientar-se que o Estado legal estribado na lei para limitar o poder real absoluto alcançou um patamar de segurança, tornando o império da lei de extrema relevância. Contudo, é no Estado democrático e social que a legalidade torna-se ainda mais importante.

O Estado democrático advém da sujeição do Estado "à vontade popular e aos fins propostos pelos cidadãos" (BASTOS, 1998, p. 157), não admite que as pessoas estejam submetidas ao arbítrio e à ilegalidade. A titularidade do poder é do povo por imposição de lei que contém a força estatal. Neste modelo, o povo deve ser respeitado 
e considerado, pois o Parlamento (com quem o Executivo divide o poder) representa as pessoas (BONAVIDES, 2000, p. 602 e ss).

E a adjetivação 'social' ao Estado democrático acresce legalmente o dever de melhores condições de trabalho, divisão de renda, seguridade social e cultura (TAVARES, 2014, p. 838-840), que formula o Estado de bem-estar social no seu aspecto sociocultural.

Estas melhoras ao modelo de legislativo estão formuladas legalmente para fins de garantia, de segurança jurídica, de estabilidade e de contenção de poder.

E as leis não podem ser feitas - dada sua relevância - com vazio de conteúdo. É justamente o oposto. O conteúdo deve ser claro e protetivo.

O princípio da legalidade estrita impõe a obediência à regras de confecção da linguagem legislativa para impedir extensões indeterminadas, palavras valorativas, vagas e conter antinomias semânticas. As normas devem ter espaço de denotação exaustivo (FERRAJOLI, 2014, p.117). Nas palavras de Luigi Ferrajoli (2014, p.505):

[...] as garantias oferecidas pelo modelo cognitivista aqui delineado dependem em grande medida da semântica das linguagens legal e jurisdicional, a análise e a crítica de tais linguagens podem representar um precioso instrumento de crítica das hodiernas involuções autoritárias, além de servir à elaboração de técnicas legislativas e judiciárias mais rigorosas.

A idealização dessa relevância da lei e de sua forma diminuem o espaço de manobra interpretativa para minoração de direitos fundamentais e de personalidade.

\subsection{GARANTISMO E A SEPARAÇÃO ENTRE DIREITO E MORAL}

A existência de textos vagos a serem submetidos a proporcionalidade permite que escolhas morais do julgador orientem a decisão. São criadas escolhas "justas" aos olhos de quem dá. E isso se dá mesmo que a decisão seja abertamente imoral, injusta, ilegal ou inconstitucional (FERRAJOLI, 2012, p.23). 
Contudo, na teoria do positivismo reforçado pela estrita legalidade, a conexão do direito com a moral não é admitida serenamente, como no pensamento chamado de neonaturalista ou principialista.

As correntes teóricas nomeadas de principialistas pelo autor do garantismo são aquelas de marca não positivista, que permitem intensa discricionariedade, valendo-se de indeterminação de sentido das normas, bem como admitem a conexão entre direito e moral.

O constitucionalismo garantista é, de fato, um positivismo reforçado; não admite a junção de moral e Direito para evitar-se um absolutismo moral que varre opiniões diferentes à do julgador, ainda que seja esta mesma opinião de quem julga contra a Constituição e outras fontes.

A separação entre direito e moral dá-se para garantir que a atividade judiciária seja submetida exclusivamente à lei constitucional e infraconstitucional.

\subsection{DEMOCRACIA SUBSTANCIAL}

O garantismo concebe um sentido fraco ou lato de Estado (legal, legislativo) com a lei produzida regularmente, causando validade e a eficácia de uma norma, pouco importando seu conteúdo, seu sentido.

Por sua vez, em sentido forte ou stricto de Estado (constitucional, democrático e social de Direito) a lei é condicionada por outras normas que estabelecem limites e conteúdos (FERRAJOLI, 2011, p. 461/462).

E estas normas, bem construídas semanticamente, sem imprecisão de sentido, devem ter como parâmetro outras normas, os direitos fundamentais. Só assim são válidas (FERRAJOLI, 2011, p. 32).

Os direitos fundamentais, ao serem respeitados, concretizam uma modelo de democracia que não é só formal e sim material (ROSA, 2011, p. 5).

$E$ os direitos fundamentais, assim como os de personalidade, tem a mesma fonte, a dignidade da pessoa humana. E dela, em sua instância, depende a democracia material e o sentido forte de Estado. 
Estes direitos encontram-se situados no que o autor chama de esfera do não decidível (ROSA, 2011, p. 7). Os direitos não estão disponíveis para manipulação discursiva ou para ponderações desregradas.

Logo, o garantismo confere normatividade forte aos direitos fundamentais e de personalidade. Deve-se atentar ao fato de que, conquanto o termo remeta a jurista do século XVIII (TRINDADE, 2012), o garantismo é uma teoria que visa proteger a pessoa como centro do Ordenamento (CADEMARTORI, 2007, p. 91).

$O$ modelo de Estado arvorado na teoria de Luigi Ferrajoli é detentor de poder, mas também de dever de abstenção e de proteção positiva em favor da pessoa. A soberania popular, a legitimação dos representantes via eleição periódica com pluralismo de opções, a submissão dos governantes à lei e à Constituição, o controle judicial de decisões, a responsabilidade por atos, a preservação da Constituição, a separação de funções, a função promocional do Poder Público para preservação de direitos individuais e sociais, o aumento de organizações socioculturais, assim também a tutela de direitos e garantias individuais são marcas desta teoria (FERRAJOLI, 2011, p. 128).

Resultado do pensamento do autor de Direito e Razão em diminuição de poder do Estado e maior proteção à pessoa (CASTALDELLI SILVA; RIBAS DE PAULO, 2019, p. 175-195). Inclusive, com o máximo de construção de garantias e direitos fundamentais, amplificando-os a cada decisão (CADEMARTORI, 2016, p. 311-345).

\section{CONSIDERAÇÕES FINAIS}

Distante de ser uma teoria penal, ligada à impunidade, a abolição do sistema criminal ou a defesa exclusiva de processados, pode-se notar que o garantismo jurídico é um positivismo reforçado que se destina a proteger a pessoa. 
Isso porque é um modelo centrado na dignidade, o mesmo valor estruturante da Constituição e que orienta a atuação do Direito.

Ademais, é o pensamento de Luigi Ferrajoli estruturado de modo a promover o condicionamento de normas por outras normas, estas são os direitos fundamentais e, pode-se dizer, de personalidade.

Neste cenário, a proteção aumenta e o Estado tem minorado seu poder diante da norma, bem escrita, não sendo sujeita à ponderação moralista e despida de rigor científico.

A democracia substancial, pretendida pelo jusfilósofo italiano, é viável racionalmente como um modelo de direito que premia a pessoa, a segurança jurídica e a estabilidade, evitando desmandos, sabotagem à Constituição e a relativização total.

\section{REFERÊNCIAS}

ABBOUD, Georges; CARNIO, Henrique Garbellini; OLIVEIRA, Rafael Tomaz de. Introdução à Teoria e Filosofia do Direito. 3 ed. São Paulo: Revista dos Tribunais, 2015.

ABBOUD, Georges. Jurisdição Constitucional e Direitos Fundamentais, São Paulo: RT, 2011.

ALEXY, Robert. Derechosociales y ponderación. 2. ed. Madrid: Fundación Coloquio Jurídico Europeo, 2009.

BARROS, Suzana de Toledo. O Princípio da Proporcionalidade e o controle de constitucionalidade das leis restritivas de Direitos Fundamentais. 3 ed. Brasília: Brasília Jurídica, 2003.

BASTOS, Celso Ribeiro. Curso de direito constitucional. 19. ed. São Paulo: Saraiva, 1998.

BITTAR, Carlos Alberto. Os Direitos da Personalidade. Rio de Janeiro: Forense Universitária, 1995.

BONAVIDES, Paulo. Ciência política. 10. ed. São Paulo: Malheiros, 2000. 
BONILLA SÁNCHEZ, Juan José. Personas y derechos de lapersonalidad. Madrid: Reus, 2010.

CADEMARTORI, Sergio. Estado de Direito e Legitimidade: uma abordagem garantista. 2 ed. Campinas: Millennium, 2007.

CADEMARTORI, Sérgio Urqukart de. MIRANDA, José Alberto Antunes de. Globalização, constituição e política externa: analise comparada da participação cidadã no Brasil, Chile e Colombia. Revista do Direito Público, Londrina, v. 11, n. 3, p.311-345, dez. 2016. DOI: 10.5433/1980-511X.2016v11n3p311. ISSN: 1980-511X.

CANOTILHO, J. J. Gomes. Direito Constitucional e Teoria da Constituição. 4. ed. Coimbra: Almedina, 1998.

CARBONELL, Miguel. El principio da proporcionalidad y lainterpretación constitucional. Quito: Ministerio de Justicia y Derechos humanos, 2008.

CARNIO, Henrique Garbellini. Princípios da porporcionalidade e da razoabilidade: apontamentos a partir da teoria alemã de proporcionalidade. In: Revista Jurídica UNIARAXÁ, Araxá, v. 15, n. 14, p. 101-112, 2011.

CASTALDELLI SILVA, VALINE; RIBAS DE PAULO, ALEXANDRE . Uma visão garantista sobre prova penal produzida de ofício pelo magistrado frente ao processo penal constitucional. Revista jurídica Cesumar. MESTRADO, v. 19, p. 175-195, 2019.

COMTE-SPONVILLE, André. A Sabedoria dos Modernos. São Paulo: Martins Fontes, 1999.

DWORKIN, Ronald. Levando os direitos a sério. Trad. Nelson Boeira. São Paulo: Martins Fontes, 2002.

FACHIN, Luiz Edson. Estatuto Jurídico do Patrimônio Mínimo. Rio de Janeiro: Renovar, 2001.

FERMENTÃO, Cleide Aparecida Gomes Rodrigues. Os direitos da personalidade como direitos essenciais e a subjetividade do direito. Revista Jurídica CESUMAR. Mestrado, v. 6, p. 241-266, 2006.

FERRAJOLI, Luigi. Constitucionalismo principialista y constitucionalismo garantista. DOXA, Cuadernos de Filosofía del Derecho, n. 34, 2011.

. Direito e Razão. Teoria do Garantismo Penal. 4 ed. São Paulo: RT, 2014.

Garantismo, hermenêutica e (neo) constitucionalismo: um debate com Luigi Ferrajoli. Porto Alegre: Livraria do Advogado, 2012. 
. La democracia a través de losderechos: El constitucionalismo garantista como modelo teórico y como proyecto político. Trad. Perfecto Andrés lbañez. Madrid: Editorial Trotta, 2014.

. Principia luris. Teoríadelderecho y de la democracia. Teoríadelderecho. Madrid: Editorial Trotta, 2011.

. Poderes salvajes. La crisis de la democracia constitucional. Trad. Perfecto Andrés Ibañez. Madrid: MinimaTrotta, 2011.

GUASTINI, Riccardo. Das fontes às normas. Trad. Edson Bini. São Paulo: Quartier Latina, 2005.

GUERRA FILHO, Willis Santiago; CARNIO, Henrique Garbellini. Teoria Política do Direito. 2 ed. São Paulo: RT, 2013.

HABERMAS, Jürgen. Direito e Democracia: entre facticidade e validade. v. I. Rio de Janeiro: Tempo Brasileiro, 1997.

HASSEMER, Winfried. Direito penal: Fundamentos, estrutura, política. Porto Alegre: Sergio Antonio Fabris, 2008.

LUISI, Luiz. Os Princípios Constitucionais Penais. 2 ed. Porto Alegre: Sergio Antonio Fabris Editor, 2003.

MAIHOFER, Werner. Estado de derecho y dignidad humana. Trad. José Luis Guzmán Dalbora. Montevideo-Buenos Aires: BdeF-Julio Cesar Faria Editor, 2008.

OLIVEIRA, José Sebastião de. Fundamentos constitucionais do direito de família. São Paulo: RT, 200.

PRADO, Luiz Regis. Bem jurídico-penal e Constituição. 8 ed. Rio de Janeiro: Forense, 2019.

. Tratado de Direito Penal Brasileiro. Vol. I. São Paulo: RT, 2014.

ROSA, Alexandre Morais da. Garantismo jurídico e controle de constitucionalidade material: aportes hermenêuticos. 2. ed. Rio de Janeiro: Lumen Juris, 2011, p. 5.

SARLET, Ingo Wolfgang. Dignidade da pessoa humana e direitos fundamentais na Constituição Federal de 1988. 9. ed. rev. atual. Porto Alegre: Livraria do Advogado, 2012. 
STRIQUER SOARES, Marcos Antônio; LIMA, P. R. Decisão judiciária: estudo do pensamento de Robert Alexy. Revista do Direito Público (Londrina), v. 7, p. 3-16, 2012.

SZANIAWSKI, Elimar. Direitos de personalidade e sua Tutela. 2. ed. São Paulo: Revista dos Tribunais, 2005.

TAVARES, André Ramos. Curso de direito constitucional. São Paulo: Saraiva, 2002.

. Manual do Poder Judiciário brasileiro. São Paulo: Saraiva, 2012.

TRINDADE, André Karam. Revisitando o garantismo de Luigi Ferrajoli: uma discussão sobre metateoria, teoria do direito e filosofia política. In: Revista Eletrônica da Faculdade de Direito de Franca. v. 5. n. 1. 2012. 